\title{
SOBRE ALGUNS FORAMINIFERA DA COSTA DO ESTADO DE SÃO PAULO
}

\author{
J. de Paiva Carvalho e \\ E. M. Leclerc Chermont
}

Efetuando estudos planctonológicos ao longo da costa paulista, entre os anos de 1935-1945, um de nós teve ocasião de colecionar amostras de Foraminifera, que não foram então estudadas por absoluta falta de bibliografia. Por isso mesmo, fazendo referência a essa Subordem (Carvalho 1939, p. 35-36), dissemos: "Apenas um exemplar da família Rotalidae, como já foi antes mencionado, me foi dado encontrar no plancton de julho. Aliás, não me preocupei muito com êsses amebozoários, dos quais, no material recém recolhido, figuravam algumas formas de cascas calcáreas contendo inclusões de pequeníssimos grãos de areia. Em janeiro, obtive também uma forma pertencente à família Textulinidae". Na ocasião, as investigações relativas ao plancton eram conduzidas de maneira assaz precária e com reiteradas soluções de continuidade, em virtude da ausência completa de elementos materiais. Sòmente a partir de 1948 foi possível ampliar as pesquisas, ocasião em que começou-se a promover o exame das areias das praias, dos bancos submersos e do lôdo dos fundos; dêsse modo, colecionaram-se amostras nas desembocaduras dos rios, nas entradas de barras e canais. O material assim obtido passou a ser conservado em coleções seriadas, onde aguardou momento propício para o seu exame.

Em 1950-1951, em virtude de estudos levados a cabo pela direção do Instituto a respeito da formação geológica da região lagunar compreendida entre as cidades de Iguape e Cananéia, no litoral sul do E. de São Paulo, passamos a pesquisar mais detidamente o acêrvo capturado. Um de nós (Leclerc-Chermont) encarregou-se, também de promover a seleção do material, incluindo em lâminas microscópicas os espécimes mais característicos da costa paulista. Dessa maneira, pudemos confeccionar a primeira lista dos foraminiferos mais comuns da costa do Estado, da qual constam as seguintes espécies:

Quinqueloculina candeiana d'Orbigny

Quinqueloculina lamarckiana d'Orbigny

Quinqueloculina laevigata d'Orbigny

Quinqueloculina costata d'Orbigny 
Pyrgo subsphaerica (d'Orbigny)

Triloculina circularis Bornemann

Cornuscopira involvens Reuss

Trochamina peruviana Cushman \& Kellet?

Nodosaria catesbyi d'Orbigny

Lagena perlucida (Montagu)

Lagena orbignyana (Seguenza)

Guttulina lactea (Walker \& Jacob)?

Nonion grateloupi (d'Orbigny)

Elphidium sagrum (d'Orbigny)

Buliminella parallela Cushman \& Parker

Bulimina patagonica d'Orbigny

Bolivina dilatata Reuss?

Bolivina plicatella Cushman

Bolivina striatulla Cushman

Siphogerina raphanus (Parker \& Jones)

Spirilina vivipara Ehrb., var. densepunctata Cushman

Discorbis floridana Cushman

Discorbis mira Cushman

Discorbis nitida (Williamson)

Discorbis sp.,

Cancris sagra (d'Orbigny)

Anomalina sp.,

Conquanto o nosso objetivo, ao encetarmos o exame dos Foraminifera da costa paulista, não fôsse pròpriamente o de estudá-los sob o ponto de vista taxonômico, desde que o nosso maior interêsse residia na investigação ecológica e na determinação da idade de certos sedimentos existentes no litoral sul, especialmente na baía de Trapandé e suas adjacências, deliberamos investigar também o grupo sob o seu aspecto sistemático, ponto de partida para se efetuar o estudo da biologia e da ecologia de algumas espécies que mais de perto nos interessam. Em primeiro lugar, pois, estamos verificando a ocorrência de determinadas formas, nas diversas estações do ano, acompanhando a sua distribuição, quer no estado planctônico, quer no sessil, tanto nas areias das praias como nos sedimentos dos fundos. Temos a intenção de examinar, muito breve, a fauna das ilhas costeiras e acompanhar a sua penetração na zona de água salobra, até o domínio de água doce.

Até agora, além do material de fundo obtido em pontos esparsos da plataforma continental, efetuamos dragagens na entrada da barra de Cananéia na baía de Trapandé e no chamado Mar do Cubatão. As praias mais exploradas têm sido as das Flexeiras, em São Sebastião, as do Boqueirão, em Santos, a de Itararé, em São Vicente, a Praia de Fora, na 
Ilha Comprida, em Cananéia e várias outras pequenas formações arenosas existentes à entrada da barra de Cananéia.

Ainda é muito cêdo para que se possa dizer algo de definitivo a respeito do que ocorre nos locais até agora pesquisados. Contudo, algumas considerações preliminares já podem ser expendidas a cêrea do que temos verificado nesses locais, como segue:

Litoral norte (São Sebastião) - Abundância de material em qualquer praia. A maior coleta, tanto sob o ponto de vista qualitativo, como sob o quantitativo, verificou-se na Praia das Flexeiras, situada entre as pontas do Recife e do Araçá.

Centro (Santos e São Vicente) - Revelaram-se produtivas as praias existentes entre o Boqueirão e a Praia de Itararé, apresentando interêsse especial o local situado sob a ponte que dá acesso à Ilha Porchat. O material colhido na Ponta da Praia, nas proximidades do canal $n .^{\circ} 6$, foi também interessante.

Litoral sul (Cananéia) - Não se mostrou produtiva a extremidade sul da Praia de Fora, na Ilha Comprida, ao menos nas épocas em que foi por nós visitada. O mesmo se pode dizer quanto às demais formações arenosas que se situam desde a entrada da barra até o Mar de Cananéia. A maior abundância de foraminiferos verificou-se sempre em praias de areia lodosa. Nada, até o momento, obtivemos em relação ao Mar de Cubatão, de onde, contudo, conservamos algumas amostras ainda não examinadas.

Uma das espécies ocorrentes em quase tôda a faixa litorânea por nós pesquisada é, sem dúvida, Nonion grateloupi. Mais freqüente e abundante do que ela foi Bulimina patagonica, encontrada na Praia das Flexeiras e na de Itararé. Também muito comuns foram os representantes do gênero Quinqueloculina, sobretudo Q. candeiana e Q. lamarckiana. Dentre as espécies mais raras, figuraram: Buliminella parallela, Bolivina plicatella, Lagena perlucida e L. orbignyana. Temos dúvidas quanto à determinação exata das espécies que se seguem: Trochamina peruviana, T. globigeriformis e Bolivina dilatata. Por ser ainda deficiente a literatura que temos em mãos, não nos foi possível efetuar a determinação de um exemplar do gênero Discorbis e de outro do gênero Anomalina.

Via de regra, pode-se dizer que a coleta de material pelágico revelouse muito pobre. Por isso, desde logo, passamos a nos preocupar com a captura por meio de dragagens ou então com a simples coleta de espécimes depositados sôbre as areias das praias. A falta de uma embarcação apropriada para operações ao largo, impediu-nos de levar a investigação sistemàticamente não só até à plataforma das ilhas espalhadas pelo nosso litoral, como também impossibilitou-nos o colecionamento de formas sesseis e de outras que se fixam temporàriamente sôbre vegetais ou outros subs- 
tratos, durante alguns estágios da sua vida. É de se presumir, por exemplo, que um exame detalhado feito nos campos de algas ou sôbre hidróides existentes nas proximidades da costa, nos dê a conhecer a presença de exemplares de Planorbulina, Sorites e outras espécies ainda não destacadas de sua base para iniciarem a fase de vida livre.

A coleta de material de praia, objeto do presente estudo, foi feita por meio de fraseos tipo Borrel, raspando-se a superfície arenosa, recém banhada pelas vagas, logo em seguida ao recúo das ondas. Nas barras, canais ou regiões profundas mais afastadas da costa, utilizaram-se dragas diversas, bem como pegadores de lôdo. O material assim obtido foi estudado logo a seguir ou conservado em álcool $70 \%$, para ser examinado, ùlteriormente, no laboratório. Tôdas as vêzes que se empregou o formol, teve-se o euidado de neutralizá-lo por meio do borax ou do earbonato de cálcio. Depois de lavadas em água doce, as carapaças foram guardadas em meio líquido (áleool) ou então postas a secar. Sua obtenção foi feita colocando-se pequeníssima quantidade de areia ou lôdo no fundo de vidros de relógio com diâmetro de $71 / 2 \mathrm{~cm}$, agitando-se o recipiente de modo a conseguir que o material a ser estudado ficasse na periferia ou em suspensão. Então, os espécimes foram cuidadosamente afastados para uma das bordas do vidro de relógio, de onde se promoveu a sua captura por meio de uma pipeta de ponta muito fina.

$O$ armazenamento do material foi feito empregando-se, para cada amostra, pequenos vidros com $5 \mathrm{~cm}$ de altura e diâmetro interno de $8 \mathrm{~mm}$. Passou-se, depois, a incluir o material em lâminas microseópicas medindo $76 \times 26 \mathrm{~mm}$, nas quais se colaram fragmentos de papel de desenho contendo 8 furos de $8 \mathrm{~mm}$ de diâmetro. Em cada furo depositaram-se 6, 8 ou 10 exemplares que haviam sido prèviamente imersos em xilol fenicado e, sôbre êles, uma gôta de bálsamo do Canadá. Dispensou-se sempre o emprêgo de lamínulas. Assim, continuou-se a separação do conteúdo das amostras recebidas até fins de dezembro de 1951. O número de exemplares montou a 3.200 , dos quais 659 acham-se abrigados em 19 lâminas idênticas às acima referidas.

Cabe-nos agradecer, aqui, à Exma. Sra. Da. Eveline du Bois-Reymond Marcus e ao Sr. Prof. Ernesto Marcus, pela gentileza da remessa do material de Pôrto-Novo. Também ao Sr. Clarimundo de Jesus, técnico de laboratório do Instituto Oceanográfico, somos muito gratos pelo material colhido na praia de Itararé, em São Vicente.

RELAÇ̃̃o DAS ESPÉCIES

Família Miliolidae

Gênero Quinqueloculina d'Orbigny, 1826

Quinqueloculina candeiana d'Orbigny

Est. I, fig. 1, $a, b$ e $c$

Quinqueloculina candeiana Cushman 1929, p. 27, est. III, fig. 1, $a-b-c$; Cushman \& Parker 1931, p. 4, est. I, fig. 10, a-c; Pinto 1950 , p. 15 , est. $X$, fig. $3-4$. 
OCORRÊncIa: Ubatuba, em 16-8-47. Fundo de lôdo e areia fina, com fragmentos de Ostracoda. Foi examinado um exemplar. Vários espécimes da Praia das Flexeiras foram obtidos em 30-9-51, em areia lodosa. Oito representantes desta espécie foram colhidos na Praia de Itararé, em 19-9-51, sôbre areia ligeiramente lodosa.

Profundidade: Capturaram-se mais alguns exemplares em fundos de 10 a 12 metros, nas circunvizinhanças de Caraguatatuba.

Esta espécie típica das Índias Ocidentais é muito semelhante a Quinqueloculina lamarckiana, sendo, porém, mais longa e dotada de pescoço mais comprido. A carapaça mede, de comprimento, quase o dôbro da largura; as eâmaras, distintas umas das outras, têm formato triangular, quando vistas em seção transversa, sendo providas de suturas bem evidentes; o pescoço é saliente; as arestas da carapaça são bem marcadas, possuindo esta paredes lisas; a abertura é um tanto pequena, provida de dente simples, ligeiramente embotado na extremidade.

Porte : 0.69 - 0.71 de comprimento.

Distribuição geográfica: Índias Ocidentais, Tortugas, Pôrto Rico, (Cushman \& Parker); Oceano Atlântico, Oceano Índico, canal de Gêba, Bolama, proximidades da Ponta Colonia e farol da Pedralua, na Guiné Portuguesa (Pinto). Brasil: Tlha de Paquetá, Niterói (Cushman \& Parker) Ubatuba, São Sebastião e Santos.

\section{Quinqueloculina lamarckiana d'Orbigny}

Est. I, fig. 2, $a, b$, e $c$

Quinqueloculina cuvieriana Brady 1884, vol. IX, p. 162, est. V, fig. 12, a-c; Quinqueloculina lamarckiana Cushman 1929, p. 26 , est. II, fig. $6, a-c ; 1932$, p. 24 , est. VI, fig. 2 , $a-c$; Cushman \& Parker 1931, p. 4, est. I, fig. 7, a-c; Pinto 1950 , p. 15 , fig. $7-8$

Ocorrência: Cananéia, em frente à Ponta da Trincheira, em 16-8-51. Fundo de areia fina, com camada superficial de lôdo, fragmentos muito pequenos de conchas, espículas de equinodermas e carapaças de $\boldsymbol{O}$ stracoda. Foram examinados 4 exemplares. Pôrto Novo, $\mathrm{km} 222$ da estrada de São Sebastião, em 26-1-52. Foi examinado um exemplar proveniente de mar razo.

Profundidade: De 7 a 8 metros, em frente à Ponta da Trincheira. Espécie também característica das Índias Ocidentais, possue concha com largura quase igual ao comprimento, apresentando ligeira depressão nas suturas; as paredes são lisas e, nos dois exemplares por nós examinados, achavam-se um tanto gastas; as câmaras são bem evidentes e, vistas em seção transversa, dão aspecto triangular, embora os ângulos sejam subagudos; pescoço curto; abertura em forma de ferradura, com dente estreito, mais ou menos longo, terminando em nódulo ligeiramente expan- 
dido. Visto de cima, isto é, do lado da abertura, os exemplares de Cananéia aproximam-se mais do desenho de Cushman (1932, est. VI, fig. 2, c) do que dos do mesmo autor (1929, est. II, fig. $6, c)$ bem como do de Cushman \& Parker (1931, est. I, fig. 7, c) embora no mesmo plano, provàvelmente por se ter gasto, a maioria das carapaças deixam de apresentar angulosidades.

Porte : 1 - $1.6 \mathrm{~mm}$ de comprimento.

Distribuição geográfica: Jamaica, Cuba, Martinica, baía de Sibuko, Bornéo, Makyan, Gillolo, Mar' das Molucas, estreito de Buton, Bolama, proximidades do farol da Pedralua, na Guiné Portuguesa (Pinto); Ilhas Britânicas, Índias Ocidentais, Indo-Pacífico (Cushman). Brasil : Ilha de Paquetá, ao largo da Ilha do Governador, na baía de Guanabara no Rio de Janeiro (Cushman \& Parker); Cananéia e São Sebastião.

\section{Quinqueloculina laevigata d'Orbigny}

$$
\text { Est. I, fig, } 3, a, b \text { e } c
$$

Quinqueloculina laevigata Cushman 1929, p. 30, est. IV, fig. 3, a-c; Cushman \& Parker 1931, p. 5, est. I, fig. 5-6; Pinto 1950 , p. 13 , est. I, fig. 2.

OcorrênCIA: Caraguatatuba (data ilegível). Fundo de areia fina, com fragmentos de moluscos. Foi capturado um exemplar.

Profundidade: De 4 a 5 metros.

Carapaça cêrea de $21 / 2$ vêzes mais longa do que larga, provida de pescoço curto; câmaras bem distintas, com faces externas arredondadas; paredes polidas, mas não totalmente lisas, apresentando leves traços de ranhuras longitudinais e perceptíveis de ambos os lados.

Porte : $0.50 \mathrm{~mm}$ de comprimento.

Distribuição geográfica : Índias Ocidentais, Oceano Atlântico (Cushman) proximidades do farol de Pedralua, na Guiné Portuguesa (Pinto); Oceano Atlântico (Pinto). Brasil : Ilha de Paquetá, Niterói, ao largo da Ilha do Governador na baía do Guanabara no Rio de Janeiro (Cushman \& Parker); Caraguatatuba.

\section{Quinqueloculina costata d'Orbigny}

Quinqueloculina costata Cushman 1929, p. 31, est. III, fig. $7, a-c ; 1947$, est. 14, fig. $5, a-b-c$; Pinto 1950 , p. 14, est. IX, fig. 3 .

Ocorrência: Praia das Flexeiras, em 30-9-51. Fundo de areia lodosa contendo muita mica. Foram examinados 18 exemplares. Pôrto Novo, $\mathrm{km} 222$ da estrada de São Sebastião. Foi examinado um exemplar proveniente de mar razo. 
Espécie dotada de carapaça alongada, com a periferia arredondada com câmaras achatadas e suturas um tanto deprimidas; pescoço curto; abertura provida de dente pequeno com a extremidade distal ligeiramente piriforme.

Porte: $0.38-0.51 \mathrm{~mm}$ de comprimento.

Distribuição geográfica: Mediterrâneo, Índias Ocidentais, Tortugas, Oceano Atlântico, Vavau Anchorage, Ilhas de Tonga e Fiji, Luvuka, Mokaujar, Nairai, Rotonga (Cushman) ; Oceano Pacífico, Guiné Portuguesa (Pinto). Brasil: Praia das Flexeiras, Pôrto Novo, em São Sebastião.

Gênero Pyrgo Defrance, 1824

Pyrgo subsphaerica (d'Orbigny)

Pyrgo subsphaerica Cushman 1929, p. 68, est. 18, fig. 1-2 ; 1931, p. 5, est. I, fig. $13, a-b$.

OCORRÊNCIA: Praia das Flexeiras, em 30-9-51. Em areia lodosa contendo muita mica. Praia de Itararé, em 19-9-51, sôbre areia fina com detritos orgânicos e earapaças de moluseos. Foram examinados, ao todo, 22 exemplares.

Carapaça mais ou menos piriforme, muito pequena, um pouco mais comprida do que larga e paredes lisas, polidas e finas, dotadas de câmaras arredondadas; abertura ovalada ou mais ou menos elipsoidal com dentes bífidos. Cushman (1931, p. 5) diz que a espécie "parece ser muito rara ao longo da costa da América do Sul', O autor identificou-a ao largo da Ilha do Governador, em fundo lodoso, com fragmentos de conchas. Nas regiões por nós pesquisadas, conquanto ela realmente não seja muito comum, não é porém muito rara.

PoRTE : $0.48-0.52 \mathrm{~mm}$ de comprimento.

Distribuição geográfica: Índias Ocidentais, Jamaica, Cuba, Pôrto Rico, Tortugas, costa da Flórida e Bahmas (Cushman). Brasil: baía de Guanabara no Rio de Janeiro (Cushman); Praia das Flexeiras, em São Sebastião e Praia de Itararé, em São Vicente.

Gênero Triloculina d'Orbigny, 1826

Triloculina circularis Bornemann

Est. I, fig. $4, a, b$ e $c$

Miliolina circularis Brady 1884, vol. IX, p. 169, est. IV, fig. $3, a-c$.

Triloculina circularis Cushman 1929, p. 58, est. XIII, fig. 67, est. XIV, fig. 1-2; Cushman \& Parker 1931, p. 5, est. I, fig. 12 , a-c; Pinto 1950 , p. 18 , est. XII, fig. 5. 
Ocorrêncla: Proximidades da Ilha Anchieta, em 13-7-47, em fundo de areia fina, com um pouco de lôdo e fragmentos de moluseos. Praia das Flexeiras, em 30-9-51, sôbre areia lodosa contendo muita mica. Foram examinados seis exemplares.

Profundidade: Cêrca de 9 a 10 metros; distante da costa entre 2 e 3 milhas nas cereanias da Ilha Anchieta.

Carapaça arredondada, dando a impressão, em uma das faces, de se tratar de um representante do gênero Quinqueloculina. Exame mais detalhado sobretudo da face oposta e, em particular, visto de cima, denuncia a abertura em forma de bôca de peixe ou crescentiforme, com dente achatado, semicireular.

Porte: $0.9-1 \mathrm{~mm}$ de comprimento.

Distribuição geográfica: Regiões temperadas, tropicais e subtropicais (Cushman); Oceano Atlântico e Índico, Ilhas Hawai, costa do Japão, canal de Gêba, perto da ilha do Rei, proximidades do farol do Pedralua e canal das Areias, no extremo opôsto a Bissau, na Guiné Portuguêsa (Pinto); Ilha Falkland (Cushman \& Parker); Ilha Anchieta, no litoral norte do E. de São Paulo.

Gênero Cornuspira Schultze, 1854

\section{Cornuspira involvens Reuss}

Cornuspira involvens Brady 1884, vol. 9, p. 200, est. XI, fig. 1-3; Cushman 1929, p. 80-82, est. XX, fig. 6-8; Cushman \& Wiekenden 1929 , vol. 75 , p. 4, est. II, fig. 3,1932 , p. 67 , est. XVI, fig. $2, a-b ; 1947$, est. XVI, fig. $2, a-b$; Cushman \& Parker 1931, p. 5, est. II, fig. 1.

OCORRÊNCIA: Praia das Flexeiras, em 30-9-51, sôbre areia lodosa, contendo muita mica. Foram capturadas 6 exemplares.

Carapaça deprimida, mais ou menos cireular, vista em plano lateral, constando de um proloculum pequeno seguido de espirais longas, de paredes calcáreas, imperforadas, finas e polidas; abertura quase do diâmetro da porção terminal do tubo. Espécie bastante característica e não muito comum, tal como foi assinalado por Cushman (1931, p. 5), ao tratar das espécies da costa atlântica da América do Sul.

PoRTE : $0.45-0.50 \mathrm{~mm}$ de comprimento.

Distribuição geográfica: Fiji, perto da Naira, Levuka, Vavau e Mokaujar Anchorage, Niau, ilhas de Tonga, Rotonga, atoll Rongelap, ilhas Marshall; pôrto Lotten, Kersail, ilhas Carolinas; Guam Anchorage, ilhas Ladrone, Pôrto William, nas Falkland (Cushman). Brasil: Praia das Flexeiras. 
Família Trochamminidae

Gênero Trochammina Parker \& Jones 1860

Est. I, fig. $5, a-b$ e $c$

Trochammina peruviana Cushman \& Kellet?

Trochammina peruviana Cushman \& Kellet 1929, p. 4, est. I, fig. 8, $a-b$; Cushman \& Parker 1931, p. 6-7, est. II, fig. 7, $a-c$.

Ocorrência: Proximidades da Ilha Vitória, no litoral norte do E. de São Paulo, em 12-4-40 ; Praia do Rabo Azedo, na Ilha de S. Sebastião, em 22-9-41. Ambos os locais com fundo de areia mais ou menos fina, com um pouco de lôdo e fragmentos de moluseos. Foram examinados dois exemplares.

Profundidade: Entre 2 e 3 metros.

Estes exemplares fortemente achatados, com cêrea de 3 espíras e mais de vinte câmaras, não permitiram exame detalhado, em virtude de se acharem completamente opacas as regiões umbilicais de ambos. Trata-se de indivíduos de carapaças trocóides, ligeiramente convexas na porção dorsal e levemente côncavas na ventral; suturas recurvadas mas não muito visíveis, na região próxima ao centro; face inferior provida de 8 a 10 lamelas, em forma de fôlha dentada, recurvadas da direita para a esquerda e terminando em ponta no centro da carapaça onde se nota imagens pouco claras mas que dão a impressão de furos dotados de margens irregulares.

PorTe : $0.45 \mathrm{~mm}$ de comprimento.

Distribuição geográfica: Europa, Peru (Cushman \& Kellet). Brasil: Ilha de Paquetá, na baía de Guanabara no Rio de Janeiro (Cushman \& Parker); Ilha Vitória, no litoral norte do E. de São Paulo.

\section{Gênero Nodosaria Lamarck, 1812}

Nodosaria catesbyi d'Orbigny

Nodosaria catesbyi Cushman 1931, p. 7, est. III, fig. 3-4.

OCoRrÊncia: Praia das Flexeiras, em 30-9-51, sôbre areia lodosa, contendo muita mica. Foram eapturados 12 exemplares.

Carapaça composta de duas câmaras formando uma espécie de garrafinha contendo um estrangulamento central; pescoşo de tamanho médio; proloculum subglobular; presença de espinha basal; suturas bem evidentes e salientes, formando nas paredes costelas recurvadas e salientes. O exemplar de São Sebastião assemelha-se à figura de Cushman (1931, est. III, fig. 3 ). 
PoRte: $0.4-0.7$.

Distribuição geográfica : Índias Ocidentais, costas da Flórida (Cushman). Brasil: ao largo da Ilha do Governador, na baía de Guanabara, no Rio de Janeiro; Praia das Flexeiras, em São Sebastião.

Gênero Lagena Walker \& Jacob, 1798

Lagena perlucida (Montagu)

Est. I, fig. 20, $a-b$

Lagena perlucida Cushman 1931, p. 8, est. III, fig. 6; 1933 , p. 20 , est. IV, fig. $6-8$; 1947 , est. XXI, fig. 18 , $a-b$; Pinto, 1950, p. 20, est. II, fig. 1.

OconRÊncIA: Praia das Flexeiras, em 30-9-51, sôbre areia lodosa, contendo muita mica. Foram eapturados 3 exemplares.

Espécie claviforme, dotada de pescoço longo, quase cilíndrico, com ranhuras ornamentando a porção basal da carapaça. A espécie de São Sebastião aproxima-se mais da figura de Cushman (1947, fig. 18, a), um tanto mais alongada e de formas menos robustas do que a que o mesmo autor exibe na estampa III, fig. 6, do seu trabalho anterior (1931, est. III, fig. 6) e concorda mais com o desenho do mesmo autor (1933, est. IV, fig. 7). O contôrno geral do exemplar de São Sebastião salvo no que se refere à porção basal, lembra muito o de $L$. laevis (Montagu).

Porte : $0.05-0.08 \mathrm{~mm}$ de comprimento.

Distribuição geográfica: Rotonga, Viva Anchorage, Fiji, PôrtoStanley, nas Falkand (Cushman). Brasil: Praia das Flexeiras.

\section{Lagena orbignyana (Seguenza)}

Lagena orbignyana Cushman 1933, p. 26, est. VI, fig. 7-8 e 11.

OcorrêncIa: Praia das Flexeiras, em 30-9-51, sôbre areia lodosa contendo muita mica. Capturou-se um único exemplar nessa praia. Pôrto Novo, km 222 da estrada de São Sebastião, em 26-1-52. Foi examinado um único exemplar, proveniente de águas razas.

Referindo-se a êste exemplar, Cushman (1933, p. 26) diz tratar-se. de uma dessas espécies nas quais se constatam formas as mais variadas. $\mathrm{O}$ nosso espécime enquadra-se bem na diagnose de $L$. orbignyana, pôsto que divirja um poueo da morfologia das figs. 1 a 5 que o autor fornece, pois não possue formato piriforme tão acentuado, aproxima-se mais da forma peculiar de L. marginata. Em virtude, porém, dos outros caracteres concordantes e da variação a que se acha freqüentemente submetida a espécie, deliberamos conservá-la dentro de $L$. orbignyana, até ùlterior verificação. 
Porte: $0.40-0.45 \mathrm{~mm}$ de comprimento.

Distribuição Geográfica: Ngarue Pass., atoll Fakarava, Hikueru e Marokau I. Britânicas, Atlântico ocidental (Cushman). Brasil : Praia das Flexeiras e Pôrto Novo, no litoral norte do E. de São Paulo.

\section{Família Polymorphinidae}

Gênero Guttulina d'Orbigny, 1826

Guttulina lactea (Walker \& Jacob)?

Est. I, fig. 6

Guttulina lactea Cushman \& Ozawa 1930, p. 43-44; Cushman \& Parker 1931, p. 9, est. III, fig. 10-11.

OCORRÊnCIA: Canal de São Sebastião, em fundo arenoso e lodoso, com pequenos fragmentos de moluseos. Foi capturado um exemplar em 12-4-40.

Profundidade: Entre 4 e 5 metros.

Carapaça oval ou, pelo menos, ligeiramente ovalada, provida de câmaras alongadas, um tanto comprimidas, com séries muito semelhantes às do gênero Quinqueloculina; suturas bem distintas; paredes lisas e translúcidas; aberturas providas de radiações.

Porte: $0.80 \mathrm{~mm}$ de comprimento.

Distribuiç̃̃o GEográficA: Inglaterra, França, Alemanha, Japão (Cushman \& Ozawa). Brasil: baía de Guanabara no Rio de Janeiro (Cushman \& Parker); canal de São Sebastião.

\section{Família Nonionidae}

Gênero Nonion Montfort, 1808

Nonion grateloupe (d'Orbigny)

Est. I, fig. 7, $a-b$

Nonion grateloupe Cushman 1930, p. 10, est. III, fig. 9-11; est. IV, fig. 1-4; Cushman \& Parker 1931, p. 10, est. II, fig. $6, a-b$.

Ocorrência: Canal de São Sebastião em 12-4-40. Fundo arenoso e lodoso, com pequenos fragmentos de carapaças de moluseos. Santos (Ponta da Praia), junto ao canal n. ${ }^{\circ}$ 6. Fundo de areia fina, sem muito detrito. Foram examinados 4 exemplares. Praia do Boqueirão, em 19-9-51. Foram examinados 2 exemplares. Pôrto Novo, $\mathrm{km} 222$ da estrada de São 
Sebastião, em 26-1-52. Foram examinados 8 exemplares colhidos em águas razas.

Profundidade: Cêrea de 3 metros, no canal de São Sebastião. A $0.80 \mathrm{~m}$, na Ponta da Praia, em Santos.

Carapaça planispiral, de simetria bilateral, provida de 12 ou 14 câmaras recurvas e alongadas, que vão decrescendo de tamanho em direção à espíra; paredes lisas, providas de finíssimas perfurações; suturas bem evidentes; abertura pequena e estreita, situada na última câmara.

PoRte: $0.59-0.61 \mathrm{~mm}$ de comprimento.

Distribuição geográfica : Franȩa, Cuba, Jamaica, Martinica, baía de Montego, Tortugas, Pôrto de San Juan, Pôrto Rico, Indias Ocidentais (Cushman). Brasil: baía de Guanabara no Rio de Janeiro (Cushman \& Parker); canal de São Sebastião, Santos e Pôrto Novo, em São Sebastião.

Gênero Elphidium Montfort, 1808

Elphidium sagrum (d'Orbigny)

Est. I, fig. 8, $a-b$

Elphidium ságrum Cushman 1930, p. 24, est. IX, fig. 5-6; Cushman \& Parker 1931, p. 10-11.

OcorRêncIA: Canal de São Sebastião em frente à praia de Siriúba, em 8-4-39. Fundo de areia fina, com fragmentos de moluscos. Foi examinado um exemplar.

Profundidade: Cêrca de 3 metros.

Exemplar de pequenas proporções, quase redondo, com os flancos convexos e a região umbilical deprimida; suturas com sulcos mais evidentes nas últimas câmaras; paredes ornamentadas por depressões evidentes; abertura provida de pequenos furos arredondados.

Porte: $0.40 \mathrm{~mm}$ de comprimento.

Distribuição geográfica: Índias Ocidentais, Cuba, Flórida, São Domingos, Bermudas, Pôrto Rico, Havana (Cushman) ; Atlântico tropical (Cushman \& Parker). Brasil: baía de Guanabara no Rio de Janeiro; (Cushman \& Parker); canal de São Sebastião.

Família Buliminidae

Gênero Buliminella Cushman, 1911

Buliminella parallela Cushman \& Parker

Est. I, fig. 9, $a-b$

Buliminella parallela Cushman 1931, p. 13-14. 
OCORRÊNCIA: Ubatuba, em 16-8-47, em frente da baía. Fundo de areia fina, com pouco lôdo, fragmentos de moluscos, algas calcáreas e carapaças de Ostracoda. Foi examinado um exemplar.

Profundidade: De 10 a 12 metros.

Carapaça alongada, com ambos os polos arredondados; eâmaras bem distintas, dando o aspecto, na face dorsal, de telhas imbricadas; paredes lisas e polidas; suturas evidentes; abertura piriforme.

Porte: $0.25 \mathrm{~mm}$ de comprimento.

Distribuição geográfica: Brasil : ilha de Paquetá, na baía de Guanabara no Rio de Janeiro (Cushman \& Parker); Ubatuba, no litoral norte do E. de São Paulo.

Gênero Bulimina d'Orbigny, 1826

\section{Bulimina patagonica d'Orbigny}

Bulimina patagonica Cushman \& Kellet 1929, vol. 75, p. 7, est. III, fig. $4, a-b$; Cushman \& Wickenden 1929, vol. 75, p. 8, est. III, fig. 11, $a$ - $b$; Cushman 1931, p. 14, est. III, fig. 14.

OcorrêncIa: Praia das Flexeiras, em 30-9-51, sôbre areia lodosa contendo muita mica. Praia de Itararé, São Vicente, em 19-9-51, sôbre areia fina com detritos de moluscos. Sob a ponte que dá acesso à Ilha Porchat, São Vicente, em 19-9-51, em areia mais ou menos grossa, com íragmentos de moluseos e detritos vegetais. Pôrto Novo, no $\mathrm{km} 222$ da estrada de São Sebastião, em 26-1-52. Foram examinados 120 exemplares.

Neste espécime que exibe carapaça em espiral, quase sempre bi ou trisegmentada, dotado de paredes calcáreas e perfuradas, bem como sutura espiral mais ou menos obsoleta, observamos extrema variação ou irregularidade, sobretudo na formação das últimas eâmaras. Nas amostras por nós examinadas, com especialidade nas das praias das Flexeiras e Itararé, esta espécie foi encontrada em muito maior abundância do que nas demais.

Porte: $0.2-0.5 \mathrm{~mm}$ de comprimento.

Distribuição geográfica: América do Sul, Perú, ao largo da Ilha de Juan Fernandez (Cushman \& Kellet). Brasil: costas sulamericanas (Cushman); Praia das Flexeiras, em São Sebastião; Praia de Itararé em São Vicente.

Gênero Bolivina d'Orbigny, 1839

Bolivina dilatata Reuss?

Bolivina dilatata Brady 1884, p. 418, est. III, fig. 20-21; Pinto 1950, p. 30, est. IV, fig. 6. 
OcorrêncIa: Praia das Flexeiras, em São Sebastião, em 30-9-51, sôbre areia lodosa, contendo muita mica. Foi examinado um exemplar.

Carapaça alongada e comprimida, provida de câmaras biseriadas paredes calcáreas e finamente perfuradas. Espécie contendo cêrca de 16 câmaras de cada lado, as do polo mais largo muito grandes, diminuindo de tamanho em direção ao polo opôsto que é quase afilado. Com êste achado, parece, portanto, ficar demonstrado que a espécie não se limita ao "Atlântico norte", conforme afirmou Brady (1884, p. 418).

Porte: $0.6 \mathrm{~mm}$ de comprimento.

Distribuição geográfica: Atlântico norte, Açores, Bermudas, Irlanda (Brady). Brasil : Praia das Flexeiras, São Sebastião, litoral norte do E. de São Paulo.

\section{Bolivina plicatella Cushman}

Est. I, fig. 10

Bolivina plicatella Cushman \& Parker 1931, p. 15-16, est. III, fig. 19.

OCORRÊNCIA: Proximidades da barra de Cananéia, em frente à Ilha Comprida. Fundo de areia fina, com algas calcáreas e fragmentos de moluscos. Capturada em 14-11-36, apresentando um só exemplar, com a porção basal danificada.

Profundidade: De 5 a 6 metros.

Carapaças pequenas, curta, comprimida, com periferia sub-águda, mais larga junto à abertura. Espécie muito bonita, com ornamentações curiosas e complexas. O nosso exemplar, conquanto de porte aparentemente mais avultado, é idêntico ao desenho exibido por Cushman \& Parker (1931, fig. 19, est. III).

Porte: Deixou de ser verificado, porque o exemplar achava-se danificado.

Distribuição geográfica: Índias Ocidentais, Flórida, costa argentina, Ilhas Falkland (Cushman \& Parker); Cananéia, no litoral sul do E. de São Paulo.

\section{Bolivina striatula Cushman}

Est. I, fig. 11, a-b

Bolivina striatula Cushman \& Parker 1931, p. 16, est. III, fig. $21, a-b$.

OCORRÊNCIA: Ubatuba, em 16-8-47. Fundo de areia fina, com um pouco de lôdo e fragmentos de moluscos. Foi examinado um exemplar. 
Profundidade: 8 metros.

Pôsto que não se trate de exemplar perfeito, desde que um dos polos apresentou-se fragmentado, supômos tratar-se da presente espécie, embora a porção média se apresente um tanto mais alargada. A conformação da abertura concorda com a peculiar à espécie típica das Indias Ocidentais e que não foi nada abundante no nosso material.

Porte: $0.8 \mathrm{~mm}$ de comprimento.

Distribuição geográfica: Brasil : ilha de Paquetá, Niterói, ao largo da ilha do Governador (Cushman \& Parker); Ubatuba, litoral norte do E. de São Paulo.

Gênero Siphogerina Schlumberger, 1883

Siphogerina raphanus (Parker \& Jones)

Est. I, rig. 12, $a$-b

Siphogerina ef raphanus Cushman \& Parker 1931, p. 17, est. III, fig. 25-26.

OCORRÊNCIA: Canal de São Sebastião, em 8-4-39. Fundo de areia mais ou menos fina, com detritos vegetais, fragmentos de carapaças de equinodermas e pequenos moluseos. Foi capturado um exemplar.

Profundidade: Entre 3 e 4 metros.

Carapaça cilíndrica e alongada, de paredes calcáreas e perfuradas, com uma espécie de colarinho ou pescoço curto; ranhuras salientes dispostas longitudinalmente; depois da região globular que se segue ao pescoço, existem como que divisões bem delimitadas, em número de 8 e ainda uma nona de largura quase idêntica à da primeira. 0 nosso exemplar assemelha-se ao figurado por Cushman \& Parker. (1931, fig. 26-a).

Porte: $0.1 \mathrm{~mm}$ de comprimento.

Distribuição Geográfica: Índias Ocidentais e Indo-Pacífico (Cushman \& Parker). Brasil: Ilha de Paquetá, Niterói, ao largo da Ilha do Governador, na baía de Guanabara no Rio de Janeiro (Cushman \& Parker). Canal de São Sebastião.

\author{
Família Rotalidae \\ Gênero Spirilina Ehrenberg, 1841 \\ Spirilina vivipara Ehrenberg var. densepunctata Cushman \\ Est. I, fig. 13, $a-b$ \\ Spirilina vivipara Ehrenberg var. densepunctata Cushman \\ 1931, Bull., 104, p. 4, est. I, fig. 5, $a$-b.
}


Ocorrência: Proximidades da Ilha Vitória, em 12-4-40. Fundo de areia fina, com algas calcáreas e fragmentos de moluscos. Foi examinado um exemplar.

Profundidade: Entre 2 e 3 metros.

Forma planispiral, achatada, provida de paredes calcáreas e numerosas perfurações. Cushman $(1931$, p. 4), ao criar essa nova variedade, baseou-se no diâmetro das circunvoluções que, nela, é maior do que na forma típica. Não tendo material para estudo comparativo, optamos pela variedade criada por êsse autor, desde que pesquisas anteriores já haviam assinalado a sua presença em águas da baía de Guanabara no Rio de Janeiro.

PORTE: Diâmetro de $0.3 \mathrm{~mm}$ de comprimento.

Distribuição geográfica: Largo Shoal, perto de San Juan, Pôrto Rico (Cushman). Brasil: Ilha de Paquetá, Niterói, ao largo da Ilha do Governador (Cushman \& Parker); Ilha Vitória, no litoral norte do E. de São Paulo.

Gênero Discorbis Lamarck, 1804

Discorbis floridana Cushman

Est. I, fig. 14, $a-b-c$

Discorbis floridana Cushman 1931, p. 21-22, est. IV, fig. 7-8; Cushman \& Parker 1931, p. 18-19, est. IV, fig. 5, a-c.

Ocorrência: Proximidades da Ilha Anchieta, em 13-7-47. Fundo de areia fina com um pouco de lôdo e restos de algas calcáreas. Foi examinado um exemplar.

Profundidade: Entre 7 e 8 metros.

Carapaça pardacenta, característica dos rotaliformes, um tanto ovalada, com a face dorsal arredondada e a ventral côncava; existência de pequeno número de eâmaras, variando de 5 a 6 , rugosas na porção dorsal e, na ventral, sòmente na periferia ; abertura ampla e arqueada, situada na base da última câmara, não sendo perceptível, no nosso exemplar, a existência de lábio.

Porte: $0.5 \mathrm{~mm}$ de comprimento.

Distribuição geográfica: Dry Tortugas, Jamaica, Índias Ocidentais (Cushman). Brasil: Tlha de Paquetá, Niterói, ao largo da Ilha do Governador, na baía de Guanabara no Rio de Janeiro (Cushman \& Parker); arredores da Iḷha Anchieta, no litoral norte do E. de São Paulo.

Discorbis mira Cushman

Est. I, fig. 15, $a-b-c$ 
Discorbis turbo Brady 1884, vol. IX, p. 642, est. LXXXVII, fig. 8, a-c; Discorbis mira Cushman 1931, p. 25-26, est. V, fig. 5, 6, a-c; Cushman \& Parker 1931, p. 19.

OCORRÊnCIA: Ubatuba, praia de Picinguaba, em 17-8-47. Fundo de areia mais ou menos fina, com pouco lôdo, algum detrito vegetal e grande quantidade de fragmentos de moluseos. Foi examinado um exemplar.

Profundidade: Cêrea de 4 metros.

Carapaça plano-convexa, de colorido branco, com o lado dorsal ligeiramente cônico e o ventral achatado e provido de prolongamentos alares que convergem para o centro; suturas oblíquas de dorso um tanto encurvadas; paredes das câmaras providas de forte asperosidade; abertura representada por um lábio levemente arqueado, situado na margem inferior da eâmara.

PoRte: $0.60-0.65 \mathrm{~mm}$ de comprimento.

Distribuiç̃o geográfica: Indias Ocidentais, Atlântico Oeidental (Cushman); ilhas do Cabo Verde, Bermudas, costa do Brasil (Brady). Brasil : baía de Guanabara no Rio de Janeiro (Cushman \& Parker) ; praia de Picinguaba, Ubatuba, no litoral norte do E. de São Paulo.

\section{Discorbis nitida (Williamson)}

Est. I, fig. 16, $a-b-c$

Discorbina nitida Wright 1889 , Ser., 6, vol. IV, p. 449 ; Discorbis nitida Cushman 1931, p. 26-27, est. VI, fig. 1, a-c ; Cushman \& Parker 1931, p. 19, est. IV, fig. 4, a-c.

Ocorrência: Proximidades da Ilha do Bom Abrigo, Cananéia, em 14-11-36. Fundo de areia fina, um tanto lodosa, com fragmentos de moluseos e carapaças de Ostracoda.

Profundidade: Cêrea de 4 metros.

Carapaça plano-convexa, de colorido branco eom tonalidades azuladas, ligeiramente arqueada na porção dorsal e achatada na ventral; câmaras em pequeno número, bem evidentes, porém não entumecidas aumentando de tamanho até a última que oeupa um pouco menos da metade do diâmetro total do exemplar; paredes lisas e providas de perfurações pequeníssimas; abertura muito pequena, em forma de ferradura, situada na base da última câmara.

Porte: $0.5 \mathrm{~mm}$ de comprimento.

Distribuição geográfica: Atlântico, costa da Bélgica, Irlanda, Ilha Faeroe (Cushman). Brasil: Ilha de Paquetá, Niterói, ao largo da Ilha do Governador, baía de Guanabara no Rio de Janeiro. (Cushman \& Parker); Ilha do Bom Abrigo, em Cananéia, no litoral sul do E. de São Paulo. 


\section{Discorbis $s p$.}

Est. I, fig. 17, $a-b-c$

OCORRÊNCIA: Cananéia, em frente à Ponta da Trincheira, em 16-8-51. Fundo de areia fina, com camada superficial de lôdo e fragmentos muito pequenos de moluscos, bem como carapaças de Ostracoda. Além do exemplar que serviu para a presente descrição, foram capturados mais seis espécimes cuja morfologia diverge um pouco da da presente espécie e que estão sendo objeto de estudo mais detalhado.

Profundidade: Entre 7 e 8 metros.

Carapaça plano-convexa, de colorido leitoso, com pontuação esparsas, de colorido alaranjado escuro; face dorsal levemente abobadada e a ventral quase plana, notando-se nesta as saliências dos prolongamentos alares cujas extremidades convergem para o umbilicum; a morfologia da última câmara lembra, de certo modo, a de Discorbis mira, porém, é mais larga do que a desta espécie; a penúltima câmara é muito ampla e de formato irregular, não se notando, com nitidez, as suturas, circunstância observada, aliás, em quase tôdas as demais; a espira das primeiras câmaras acha-se decentrada e localizada mais para o canto esquerdo, em posição inferior; o número de câmaras é de cêrea de 12 e não muito entumecidas; as paredes são lisas; a abertura encontra-se na porção inferior da última câmara que possue a parede perfurada por orfícios pequenos e redondos; os prolongamentos alares são em número de seis, tendo o da extremidade esquerda anterior o formato de um gancho cuja metade distal é dotada de pequenos orifícios.

Porte: $0.6 \mathrm{~mm}$ de comprimento.

Distribuição GEOGRÁfiCA : Encontrada sòmente na área acima assinalada.

\section{Gênero Cancris Montfort 1808}

Cancris sagra (d'Orbigny)

Est. I, fig. 18, $a-b-c$

Pulvinulina oblonga Brady, Parker \& Jones 1888, vol. 12, p. 229, est. LXVI, fig. 5 ; Cancris sagra Cushman 1931, p. 74-75 , est. XV, fig. 2, a-c; Cushman \& Parker 1931, p. 20-21; Pinto 1950 , p. 34 , est. V, fig. 7.

OCORRÊNCIA: Mar de Cananéia, próximo à junção com o Mar de Cubatão. Fundo de lôdo arenoso, de côr acinzentada. Foram examinados 3 exemplares.

Profundidade: Cêrea de 4 metros.

Carapaça trocóide e comprida, de paredes calcáreas e perfuradas; pequeno número de câmaras que não vão além de 8 ou 9 ; área umbilical 
provida de placa enorme; espira pequena, situada na porção inferior direita.

Apesar de ser tida como muito abundante no litoral atlântico, não a encontramos com freqüiência. Cushman (1931, p. 75), diz ser a presente espécie só ocorrente em água salobra, fato já observado por Brady, Parker \& Jones (1888, p. 229).

Porte: $0.8-1 \mathrm{~mm}$ de comprimento.

Distribuição geOgRÁfica: Atlântico tropieal, Tortugas, Long Reef, Miami, Pôrto Rico, (Cushman), costa da Flórida e do Brasil, Luȩão, proximidades do farol de Pedralua, canal de Gêba, quase na costa do canal das Areias, na direção de Enxudé, na Guiné Portuguesa (Pinto). Brasil: Ilha de Paquetá, Niterói, ao largo da Tlha do Governador, na baía de Guanabara, no Rio de Janeiro (Cushman \& Parker); praia de Picinguaba, Ubatuba, no litoral norte do E. de São Paulo.

\section{Gênero Anomalina d’Orbigny 1826}

Anomalina sp.

Est. I, fig. 19

Ocorrência: Ponta da Trincheira, Cananéia, em 16-8-51. Fundo de areia fina, com um pouco de lôdo e fragmentos de conchas de moluscos. Foi observado um exemplar.

\section{Profundidade: Entre 6 e 7 metros.}

Carapaça quase simétrica e espiralada, com abertura mediana; presença de 15 a 16 câmaras, bem visíveis, de ambos os lados, sendo que as três ou quatro primeiras não eram bem visíveis; suturas bem marcadas; paredes das câmaras não providas de muitas perfurações.

$\mathrm{Na}$ mesma data, foram eapturados mais quatro exemplares menores e dotados de número mais reduzido de câmaras (cêrea de 11 ou 12) as duas primeiras muito poneo visíveis, tôdas porém, bem perfuradas.

Porte: $0.8 \mathrm{~mm}$ de comprimento.

Distribuição geográfica: Só encontrada na presente área.

\section{RESUMO}

Neste trabalho, estudam-se 27 espécies de foraminiferos colecionados ao longo da costa do E. de São Paulo. Para tanto, operaram os autores em seis praias principais, como sejam: Praia do Rabo Azedo, na Ilha de São Sebastião, praia das Flexeiras, situada no eontinente, próximo à cidade de São Sebastião, Ponta da Praia e Boqueirão, em Santos, praia de Itararé, em São Vicente e Praia de Fora, na Ilha Comprida, em Cana- 
néia. Efetuaram-se eoletas no eanal de São Sebastião bem como èm regiões próximas a Caraguatatuba e Ubatuba, além de pontos situados na entrada da barra de Cananéia e adjacências das ilhas de Bom Abrigo, Vitória e Anchieta. Os trabalhos de dragagem foram efetuados em profundidades que oscilaram entre $0 \mathrm{~m} 80$ e 12 metros.

Das 27 espécies relacionadas até o presente, 21 são provenientes do litoral norte, das quais 3 ocorrem também no centro do litoral do Estado (Santos e São Vicente). Seis são da região sul da costa bandeirante (Cananéia).

Dentre as praias visitadas, as do litoral norte revelaram-se mais produtivas, salientando-se, entre tôdas, a Praia das Flexeiras. Embora menos rica, a Praia de Itararé forneceu material variado e interessantíssimo.

Em relação aos gêneros representados pelo maior número de espécies, figuram, em primeiro lugar: Quinqueloculina e Discorbis, vindo a seguir o gênero Bolivina. Embora fazendo-se representar por pequeníssimo número de exemplares, o gênero Lagena segue aos acima referidos pôsto que até agora, tenha sido representado sòmente por duas espécies. Os demais 14 figuraram, cada um, com uma só espécie.

Os autores investigaram, preliminarmente, o grupo sob o prisma puramente taxonômico para conhecimento das principais espécies ocorrentes no litoral do E. de São Paulo, tencionando prosseguir, em maior profundidade, na pesquisa biológica e, sobretudo, ecológica. Assim, investigam a ocorrência de determinadas formas nas diversas estações do ano, acompanhando a sua distribuição, tanto no estado planetônico como no sessil, quer nas praias, como nos sedimentos dos fundos, com o objetivo de conhecer a sua penetração e distribuição nos ambientes de águas salobras e doces do litoral paulista.

\section{SUMMARY}

In this paper are recorded 27 different species of Foraminifera collected along the coast of the State of São Paulo. The specimens were eollected mainly at six points: "Rabo Azedo" beach in the Island of São Sebastião; "Flexeiras"' beach, on the continent, near to the town of São Sebastião; beaches of "Ponta da Praia" and "Boqueirão" in the Bay of Santos; "Itararé" beach at São Vicente and "Praia de Fora", the beach of the "Ilha Comprida" (Long Island) at Cananéia. Collects were also effected in the channel of São Sebastião and at places near Caraguatatuba and Ubatuba, at spots located at the entrance of the bar of Cananéia and near the islands "Bom Abrigo", "Vitória" and "Anchieta". Dredgings were done at depths varying from 0.80 to 12 meters.

Of the 27 species recorded until now, 21 are from the northern coast of the State, 3 of which are present also in the central region (Santos and São Vicente); 6 species are from the southern coast of the State.

The richest collects were from the northern litoral, especially so at the beach of "Flexeira'. The beach of Itararé although poorer in abundance produced a varied and most interesting material. 
In what concerns the genera represented by the greater number of species, are in first place Quinqueloculina and Discorbis, followed by Bolivina. Next comes Lagena with up to now only two species. The remaining 14 genera are represented by only one species.

The authors studied the group only under an entirely taxonomic point of view to know which are the commonest species that occur on the coast of the State; they intend later to pursue biological and ecological researches in the group. Researches are being effected to study the oceurence of certain forms in the different seasons, their distribution, both in the planctonic and sessil stage, on the beaches and bottom deposits. aiming at discovering their penetration and distribution in brackish and fresh waters of the littoral region of the State.

\section{BIBLIOGRAFIA}

BRADY, H. B., 1884, Report on the Foraminifera dredged by H. M. s. "Challenger" during the years 1873-1878. Scientific Results. Rep. Voy. H. M. S. Challenger. Zoology, vol. 9 (texto), p. XXI +814. London.

BRADY, H. B., Parker, W. K., \& Jones, I. R., 1888, On some Foraminifera from Abrolhos Bank. Trans. Zool. Soc. London, vol. 12, p. 211-239, pl. XL-XLVII. London.

CARVALHO, J. de P., 1939, Variação do planeton da baía de Santos. Nota prévia. Bol. Biol. (Nova Série), vol. IV, n.o 1, p. 32-49. São Paulo.

CUshman, J. A., 1923, The Foraminifera of the Atlantic Ocean. Smith. Inst. U. S. Nat. Mus., Bull. 104, $\mathrm{X}+228$, pl. I-LXII. Washington.

CUSHMAN, J. A., 1929, The Foraminifera of the Atlantic Ocean. Part. 6. Smith. Inst. Bull. 104, VIII + 129, pl. I-XXII, Washington.

CUSHMAN, J. A., 1932, The Foraminifera of the tropical Pacific collections of the "Albatross", 1899-1900, Part. I. Smith. Inst. Bull., 161, V + 88, pl. I-XVII. Washington.

CUSHMAN, J. A., 1947, Foraminifera, their classification and economic use, VIII + 535, pl. I-LXVIII. Cambridge.

CUSHMAN, J. A., \& Kellet, B., 1929, Reeent foraminifera from the west coast of South America. Proe. U. S. Nat. Mus., vol. 75, art. 25, p. 1-16, pl. I-V. Washington.

CUSHMAN, J. A., \& Ozawa, Y., 1930, A monograph of the foraminiferal family Polymorphinidae recent and fossil. Proe. U. S. Nat. Mus., vol. 77, art. 6, p. 1-185, pl. I-LX. Washington.

CUSHMAN, J. A., \& Parker, F. L., 1931, Recent Foraminifera from the Atlantic coast of South America. Proe. U. S. Nat. Mus., vol. 80, art. 3, p. 1-24, pl. I-IV. Washington.

CUSHMAN, J. A., \& Wiekenden, R. T. D., 1929, Recent foraminifera from off Juan Fernandez. Proc. U. S. Nat. Mus., vol. 75, art. 9, p. 1-16, pl. I-VI. Washington.

PINTO, J. dos Santos., 1950, Foraminiferos dos sedimentos marinhos da Guiné Portuguêsa. 


\section{ESTAMPA I}

Figura 1 - Quinqueloculina candeiana d'Orbigny, $a$ e $b$, faces opostas; $c$, abertura. $\times 35$.

" $\quad 2$ - Quinqueloculina lamarckiana d'Orbigny, $a$ e $b$, faces opostas; $c$, abertura. $\times 22,5$.

" 3 - Quinqueloculina laevigata d'Orbigny, $a$ e $b$, faces opostas; $c$, abertura. $\times 80$.

" 4 - Triloculina circularis Bornemann, $a$ e $b$, faces opostas; $c$, abertura. $\times 22,5$.

" 5 - Trochammina peruviana Cushman \& Kellett, $a$ e $b$, faces opostas; $c$, vista lateral. $\times 35$.

" 6 - Guttulina lactea (Walker \& Jacob), vista de uma das faces. $\times 35$.

" 7 - Nonion grateloupe (d'Orbigny), $a$, vista de uma das faces; $b$, vista lateral. $\times 50$.

" 8 - Elphidium sagrum (d'Orbigny), $a$, vista de uma das faces; $b$, ivsta lateral. $\times 42,5$.

" 9 - Buliminella parallela Cushman \& Parker, $a$, vista de uma das faces; $b$, vista lateral. $\times 80$.

" 10 - Bolivina plicatella Cushman, vista de uma das faces. $\times 70$.

" 11 - Bolivina striatula Cushman, $a$, vista de uma das faces; $b$, abertura. $\times 75$.

" 12 - Siphogerina raphanus (Parker \& Jones), $a$, vista de uma das faces; $b$, abertura. $\times 32,5$.

13 - Spirilina vivipara Ehrenberg var. densepunctata Cushman, $a$ e $b$, faces opostas; $c$, vista lateral. $\times 55$. 14 - Discorbis floridana Cushman, $a$ e $b$, faces opostas; $c$, vista lateral. $\times 50$.

" 15 - Discorbis mira Cushman, $a$ e $b$, faces opostas; $c$, vista lateral. $\times 50$.

" 16 - Discorbis nitida (Williamson), $a$ e $b$, faces opostas; $c$, vista lateral. $\times 50$.

" $\quad 17-$ Discorbis sp., $a$ e $b$, faces opostas; $c$, vista lateral. $\times 50$.

" 18 - Cancris sagra (d'Orbigny), $a$ e $b$, faces opostas; $c$, vista lateral. $\times 35$.

" 19 - Anomalina sp., vista de uma das faces. $\times 25$.

" 20 - Lagena perlucida (Montagu), $a$, vista de uma das faces; $b$, abertura. $\times 36$. 
ESTAMPA 1
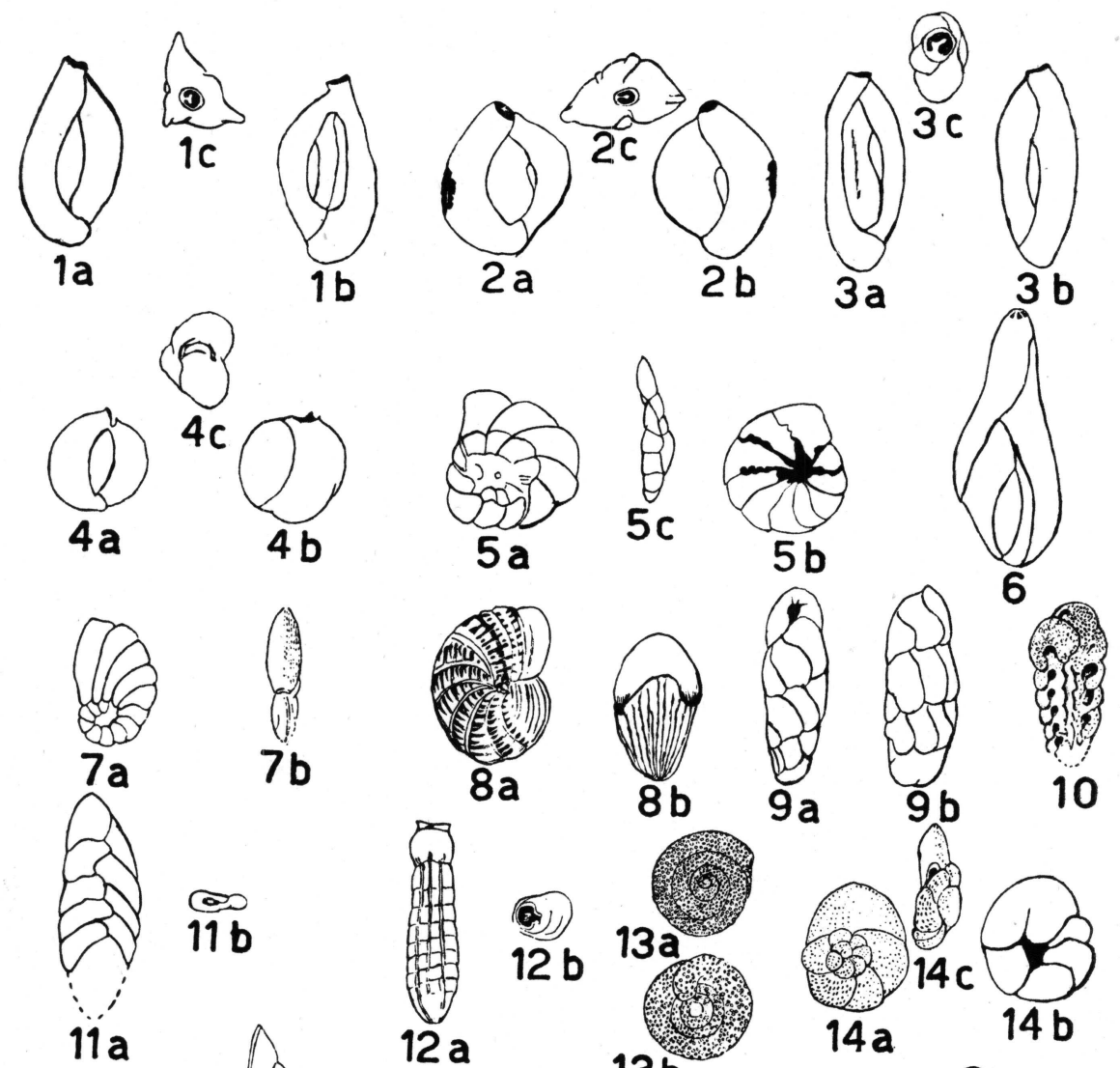

$11 b$
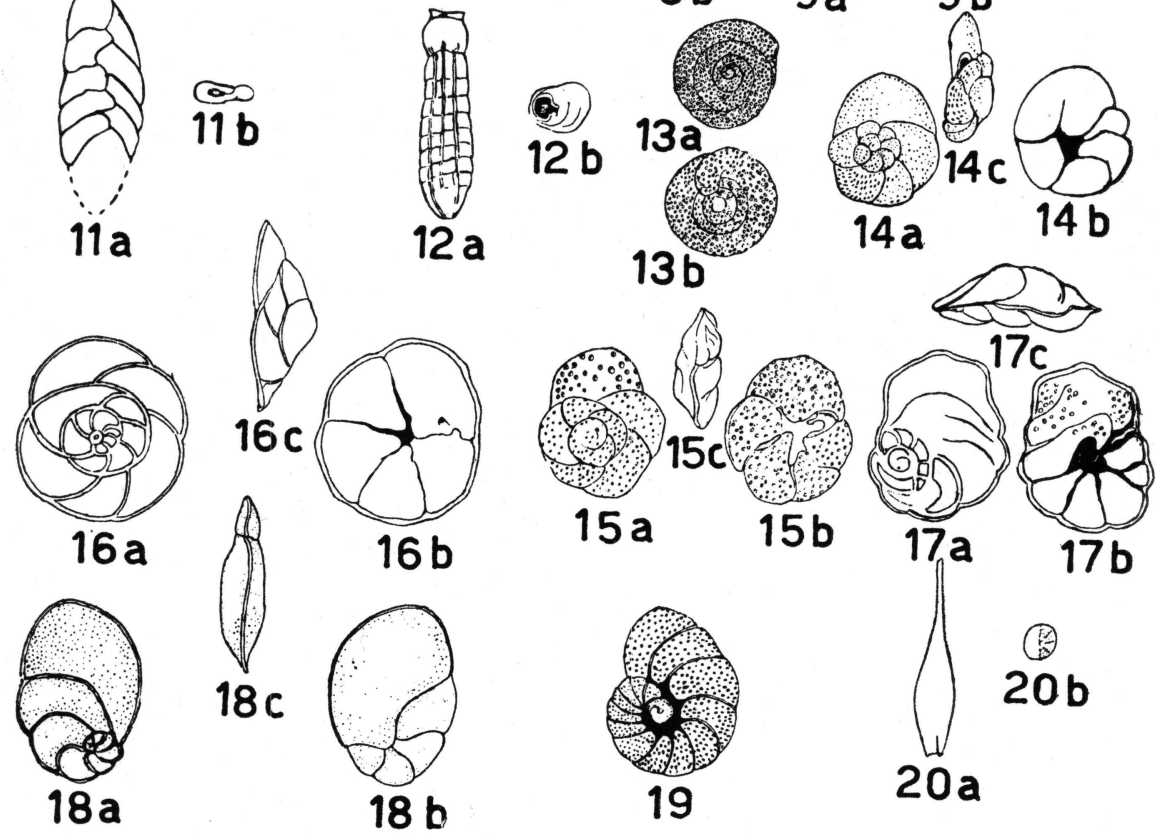

$15 \mathrm{~b} 17 \mathrm{a} \quad 17 \mathrm{~b}$

$18 \mathrm{~b}$

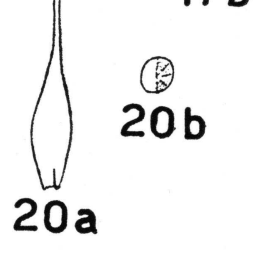

